\title{
DIREITO À MEMÓRIA, CIDADANIA CULTURAL E ENSINO DE HISTÓRIA NO CURRÍCULO OFICIAL DO ESTADO DE SÃO PAULO
}

\author{
RIGHT TO MEMORY, CULTURAL CITIZENSHIP AND HISTORY \\ TEACHING IN THE OFFICIAL CURRICULUM OF THE STATE OF SÃO
} PAULO

\author{
Jorge Eschriqui Vieira Pinto ${ }^{1}$
}

\section{Resumo:}

As contribuições das ações e dos bens culturais do passado de diversos setores sociais para a formação histórica da sociedade brasileira presentes nos programas curriculares da disciplina de História constitui-se em um fator imprescindível para o acesso universal e democrático de todos os indivíduos ao direito de constituição de uma memória individual e coletiva e para o reconhecimento da participação política de diversos agentes e grupos sociais na transformação da realidade nacional. Este artigo busca analisar no Currículo Oficial do Estado de São Paulo o papel do ensino de História para a constituição da memória e a garantia do direito à cidadania cultural pela diversidade social, étnica e cultural que compõe o corpo discente da rede estadual de educação básica.

Palavras-Chave: Memória; Cidadania Cultural; Ensino; Currículo.

\section{Abstract:}

The contributions of the actions and cultural assets of the past from various social sectors to the historical formation of Brazilian society present in the curricula of the discipline of History constitute an essential factor for the universal and democratic access of all individuals to the right of constitution of an individual and collective memory and for the recognition of the political participation of various agents and social groups in the transformation of the national reality. This article seeks to analyze in the Official Curriculum of the State of São Paulo the role of History teaching for the constitution of memory and the guarantee of the right to cultural citizenship for the social, ethnic and cultural diversity that compose the student body of the state basic education network.

Key Words: Memory; Cultural Citizenship; Teaching; Curriculum.

\footnotetext{
${ }^{1}$ Doutor em História pela Universidade Estadual Paulista (UNESP), campus de Franca -SP. Pesquisador e autor na Pós-Graduação em Metodologia do Ensino de História da Faculdade UnyLeya. Endereço eletrônico: jschriqui@yahoo.com.br
} 


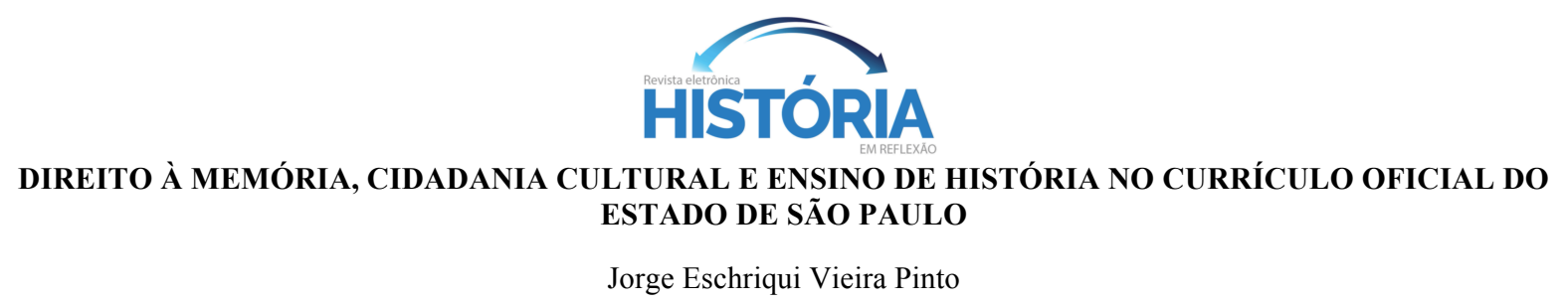

Jorge Eschriqui Vieira Pinto

A memória, onde cresce a História, que por sua vez a alimenta, procura salvar o passado para servir o presente e o futuro. Devemos trabalhar de forma a que a memória coletiva sirva para a libertação e não para a servidão dos homens (LE GOFF, 1990, p.477).

A cidadania cultural refere-se ao conjunto de direitos que proporcionam o acesso do indivíduo ao conjunto de bens emocionais, intelectuais e materiais produzidos pela humanidade, capazes de despertar nele o conhecimento de si mesmo e da realidade que o cerca por serem portadores de referência à identidade, ação e memória dos diversos grupos humanos que constituíram e constituem historicamente as sociedades. É a cidadania cultural que possibilita ao indivíduo se sentir inserido na cultura da sociedade da qual faz parte, usufruindo de seus bens culturais, produzindo cultura e se utilizando desses bens deixados por diversos grupos sociais no passado para construir a sua memória histórica que cria nele os laços de identidade com os antepassados. Portanto, três pilares sustentam o direito à cultura em uma sociedade democrática:

O direito de produção cultural parte do pressuposto de que todos os homens produzem cultura. Todos somos, direta ou indiretamente, produtores de cultura. É o direito que todo cidadão tem de exprimir sua criatividade ao produzir cultura.

O direito de acesso à cultura pressupõe a garantia de que, além de produzir cultura, todo indivíduo deve ter acesso aos bens culturais produzidos por essa mesma sociedade.

$\mathrm{E}$, finalmente, o direito à memória histórica como parte dessa concepção de Cidadania Cultural, segundo o qual todos os homens têm o direito de ter acesso aos bens materiais e imateriais que representem o seu passado, a sua tradição (FERNANDES, 1992/1993, p.271).

A discussão sobre a relação entre o exercício da cidadania cultural e a educação surge em um momento em que, como em nenhuma outra época da História da Humanidade, tornam-se mais visíveis as diferenças culturais entre vários povos e 
DIREITO À MEMÓRIA, CIDADANIA CULTURAL E ENSINO DE HISTÓRIA NO CURRÍCULO OFICIAL DO ESTADO DE SÃO PAULO

Jorge Eschriqui Vieira Pinto

sociedades por causa do desenvolvimento das Tecnologias de Informação e Comunicação (TIC) que propiciam à mídia de massa transmitir em tempo real várias notícias desde diferentes regiões do planeta, das ondas migratórias ao redor do mundo provocadas por crises humanitárias e pela busca de melhores condições de moradia, trabalho, renda, estudo, etc., da tentativa do mercado globalizado em estabelecer padrões de consumo mundiais que muitas vezes tentam passar por cima de valores e práticas culturais locais e regionais, entre outros fatores. Para Alfredo Veiga Neto,

tudo se passa como se, de repente, as metanarrativas modernas da totalidade e da unidade tenham implodido, povoando o mundo com cacos todos diferentes entre si. As sonhadas igualdade e homogeneidade modernas deram lugar à diferença. De repente, descobriu-se que Nietzsche (1996) tinha razão: “...pois não há em si nada igual...”. Então, se a escola moderna foi pensada e instituída com, entre outros, o objetivo de "equalizar" o mundo, como ficaremos diante do elogio à diferença? E como poderemos garantir, ao mesmo tempo, o direito à diferença e à manutenção da igualdade? (VEIGA NETO, 2005, p.8).

No âmbito nacional, com o processo de redemocratização do país, a partir do final da década de 1970 e durante os anos 1980, movimentos sociais de trabalhadores, mulheres, negros, homossexuais, etc. passaram a reivindicar uma maior participação nas políticas públicas por meio do reconhecimento de seu protagonismo sócio cultural e do atendimento de suas demandas pelo novo regime democrático que começava a se implantar. É nesse contexto que se inicia o debate nas esferas acadêmica, estatal e escolar sobre o papel da educação na constituição de um regime democrático no qual se reconheça o multiculturalismo e não se transforme as diferenças culturais em práticas de dominação, intolerância e preconceito, mas um campo para a aceitação do protagonismo histórico-cultural de diversos sujeitos e grupos sociais. De acordo com Alfredo Veiga Neto,

como em nenhum outro momento, parecem tornar-se cada vez mais visíveis as diferenças culturais. Igualmente, mais do que nunca, têm sido frequentes e fortes tanto os embates sobre a diferença e entre os diferentes, quanto a opressão de alguns 


\section{HISTÓRIA \\ DIREITO À MEMÓRIA, CIDADANIA CULTURAL E ENSINO DE HISTÓRIA NO CURRÍCULO OFICIAL DO ESTADO DE SÃO PAULO}

Jorge Eschriqui Vieira Pinto

sobre os outros, seja na busca da exploração econômica e material, seja nas práticas de dominação e imposição de valores, significados e sistemas simbólicos de um grupo sobre os demais.

Os muitos entendimentos de hoje sobre o que seja cultura, sobre - que seja educação e sobre as relações entre ambos se encontram no centro de tais embates. Nesse contexto, o próprio papel atribuído à educação acabou transformando a pedagogia - enquanto campo dos saberes - e a escola - enquanto instituição - em arenas privilegiadas, onde se dão violentos choques teóricos e práticos em torno de infinitas questões culturais (VEIGA NETO, 2003, p.5).

Uma educação pública comprometida com a formação e o exercício da cidadania cultural no ambiente escolar demanda políticas e ações educacionais de gestores e profissionais da área baseadas na inserção nos programas curriculares, nos materiais didáticos e no trabalho pedagógico dos bens culturais relacionados à atuação histórica (demandas, negociações, lutas e conquistas) e às práticas culturais (símbolos, valores, ideias e comportamentos) dos diversos grupos sociais responsáveis pela formação histórica da sociedade brasileira. Isso implica em uma escola pública engajada com a inclusão da pluralidade cultural em seus conteúdos disciplinares (e não exclusivamente de práticas culturais vinculadas aos dominantes) e a construção da memória coletiva a partir do estudo da participação dos diversos atores e grupos sociais na história nacional, preparando-se, assim, os alunos para o exercício da cidadania por meio do entendimento do papel histórico de todos os indivíduos e setores sociais na compreensão da realidade e intervenção consciente para a transformação da sociedade. Em outras palavras, o exercício da cidadania cultural depende de uma escola democrática e plural que não pense os conteúdos e o trabalho pedagógico em termos da difusão de uma cultura única e de padrões eurocêntricos caracterizada como universal e sinônimo de modelo "elevado" a ser seguido por todos os grupos sociais e povos ${ }^{2}$. Segundo Veiga Neto,

\footnotetext{
${ }^{2}$ A partir do século XVIII, sobretudo com a influência das ideias de intelectuais alemães como Kant, Goethe, Fichte, entre outros, foi bastante difundida na Europa a ideia de que a escola deveria propagar um modelo cultural único e universal inspirado no modo de vida e nos valores artísticos, filosóficos, espirituais, religiosos, literários, etc. de conotação branca, machista e eurocêntrica. Por conseguinte, as manifestações e produções
} 
DIREITO À MEMÓRIA, CIDADANIA CULTURAL E ENSINO DE HISTÓRIA NO CURRÍCULO OFICIAL DO ESTADO DE SÃO PAULO

Jorge Eschriqui Vieira Pinto

desde que no século XVIII alguns intelectuais alemães passaram a chamar de Kultur a sua própria contribuição para a humanidade, em termos de maneiras de estar no mundo, de produzir e apreciar obras de arte e literatura, de pensar e organizar sistemas religiosos e filosóficos - especialmente todo aquele conjunto de coisas que eles consideravam superiores e que os diferenciava do resto do mundo -, a Cultura passou a ser escrita com letra maiúscula e no singular. Maiúscula porque era vista ocupando um status muito elevado; no singular porque era entendida como única. E se era elevada e única, foi logo tomada como modelo a ser atingido pelas outras sociedades.

Veio daí, por exemplo, a diferenciação entre alta cultura e baixa cultura. Simplificando, a alta cultura passou a funcionar como um modelo - como a cultura daqueles homens cultivados que "já tinham chegado lá", ao contrário da "baixa cultura" - a cultura daqueles menos cultivados e que, por isso, "ainda não tinham chegado lá". De tal diferenciação ocuparam-se muitos pedagogos, uma vez que a educação foi - e ainda é - vista por muitos como o caminho natural para a "elevação cultural" de um povo (VEIGA NETO, 2003, p.7).

Pensar a temática da cultura de maneira preconceituosa na educação não contribui em nada para a transformação da escola em um importante instrumento de inserção social dos diversos agentes sociais e, consequentemente, para a consolidação de uma democracia baseada no exercício de direitos iguais ao acesso e difusão dos elementos culturais característicos dos diversos segmentos sociais. Pelo contrário, ao se adotar nos programas curriculares, nos materiais didáticos e nas práticas pedagógicas a noção de cultura como o resultado da produção material, artística, filosófica, científica, literária, etc. relacionada apenas aos referenciais culturais estabelecidos por setores dominantes em escala mundial e nacional, apenas se aumenta a distância entre os saberes escolares, supostamente relacionados à "alta" cultura, e os elementos culturais característicos da identidade individual e de grupo dos discentes, supostamente vinculados de forma errônea a uma "baixa" cultura,

culturais de outras sociedades não passariam de variações particulares ou degenerescências de menor importância para a tarefa da educação de moldar indivíduos e regular a sociedade (VEIGA NETO, 2003). 
DIREITO À MEMÓRIA, CIDADANIA CULTURAL E ENSINO DE HISTÓRIA NO CURRÍCULO OFICIAL DO ESTADO DE SÃO PAULO

Jorge Eschriqui Vieira Pinto

tornando os conhecimentos das disciplinas desconectados da realidade dos alunos e não contribuindo em nada para uma aprendizagem significativa.

A partir da reflexão sobre a importância da educação básica como um instrumento social para a difusão da pluralidade dos bens culturais dos vários atores e setores sociais que contribuíram para a formação da sociedade brasileira e a universalização do acesso ao direito à memória, pode-se afirmar que a disciplina de História tem uma parcela considerável de contribuição para a garantia do exercício da cidadania cultural desde que faça uma autocrítica a respeito da abordagem teórico-metodológica do lugar dos vários indivíduos, grupos e classes sociais, enquanto sujeitos/agentes da Historia, que reproduz nos programas curriculares, nos materiais didáticos e no processo de ensino e aprendizagem da educação básica. Afinal, "como suscitar neles a percepção de que são sujeitos sociais e políticos? Como tornar evidente que carências, privilégios, exclusões e opressão não são naturais nem impostas pela Providência divina?" (CHAUÍ, 1995, p.80-81).

Há uma incontestável renovação teórico-metodológica na ciência histórica produzida e difundida no meio acadêmico nacional, sobretudo, a partir do final dos anos 1970 e início da década de 1980, com a influência da História Social inglesa, destacando-se os trabalhos de Edward Thompson, que se dedica à análise histórica a partir da perspectiva dos indivíduos e grupos sociais pertencentes às camadas populares (história "vista de baixo"), e da historiografia francesa, sobretudo da terceira geração da Escola dos Annales, também chamada de Nova História, com destaque para as obras de Jacques Le Goff, que propõe novos sujeitos, novos objetos e novas abordagens para a pesquisa histórica. Apesar dessa renovação na universidade, observa-se a presença nos programas curriculares, nos materiais didáticos e nas práticas de ensino da educação básica de uma historiografia tradicional baseada na ênfase da cultura considerada "superior" e "civilizada" de matriz eurocêntrica e que prima por uma narrativa linear de acontecimentos e ações dos heróis nacionais ligados aos setores dominantes, colocando-se em segundo plano as contribuições de outros segmentos sociais no processo histórico de formação da sociedade nacional. Segundo José Ricardo Oriá Fernandes, 
DIREITO À MEMÓRIA, CIDADANIA CULTURAL E ENSINO DE HISTÓRIA NO CURRÍCULO OFICIAL DO ESTADO DE SÃO PAULO

Jorge Eschriqui Vieira Pinto

os livros didáticos, sobretudo os de História, ainda estão permeados por uma concepção positivista da historiografia brasileira, que primou pelo relato dos grandes fatos e feitos dos chamados "heróis nacionais", geralmente brancos, escamoteando, assim, a participação de outros segmentos sociais no processo histórico do país. Na maioria deles, despreza-se a participação das minorias étnicas, especialmente índios e negros. Quando aparecem nos didáticos, seja através de textos ou ilustrações, índios e negros são tratados de forma pejorativa, preconceituosa ou estereotipada.

Apesar da renovação teórico-metodológica da História nos últimos anos, o conteúdo programático dessa disciplina na escola fundamental tem primado por uma visão monocultural e eurocêntrica de nosso passado (FERNANDES, 2005, p.380).

Essa perspectiva pode ser comprovada através da análise do papel e da presença do negro e do índio ao longo da História do Brasil nos livros didáticos. Em geral, a etnia indígena aparece com muita frequência no início do processo de colonização do país, desde a chegada dos portugueses no Brasil, passando pela catequização e fundação das missões jesuíticas até o movimento das bandeiras entre meados do século XVII e início do século XVIII. Em suma, ao índio caberia a função histórica de apresentar a "nova" terra e as suas riquezas aos "descobridores" europeus, ser catequizado e "educado" nos parâmetros da cultura "civilizatória" europeia e servir como mão de obra compulsória, principalmente, no primeiro ciclo econômico (também denominado de ciclo do pau-brasil). Transcorrida a etapa inicial da colonização, praticamente o índio desaparece como protagonista na história nacional, com exceção do movimento literário romântico do século XIX, que em sintonia com a ideia propugnada pelo Estado imperial da necessidade de se construir uma identidade nacional, faz referências ao indígena como um dos elementos étnicos contribuintes para a configuração da cultura e identidade brasileira.

Situação similar acontece com o papel histórico do negro, geralmente restrito ao período da escravidão no país (1530-1888). Ao negro coube apenas a função histórica de servir como mão de obra essencial para a manutenção da economia extrativista, agrário-exportadora e predatória característica dos períodos colonial e imperial e combater e resistir à escravidão, seja através dos quilombos, seja por meio de 
DIREITO À MEMÓRIA, CIDADANIA CULTURAL E ENSINO DE HISTÓRIA NO CURRÍCULO OFICIAL DO ESTADO DE SÃO PAULO

Jorge Eschriqui Vieira Pinto

movimentos sociais e revoltas provinciais. Assinada a Lei Áurea em 13 de maio de 1888, o negro praticamente desaparece como personagem histórico nos livros didáticos, com exceção do episódio da Revolta da Chibata em 1910.

Em outras palavras, a historiografia tradicional, ainda bastante difundida nos materiais didáticos, normalmente compartilha uma perspectiva preconceituosa e restrita sobre o papel do índio e do negro na formação histórica da sociedade brasileira. Ademais, geralmente há uma análise histórica equivocada sobre a participação dessas etnias na História do Brasil, carecendo-se, portanto, de explicações sobre a real contribuição de suas culturas e a participação nos diversos fatos e fenômenos do passado nacional a partir dos olhares dos próprios indígenas e afrodescendentes. De acordo com Circe Bittencourt,

a ausência de grupos indígenas ou de escravos e seus descendentes é decorrente de uma visão política e ideológica, mas é preciso lembrar, referendada por uma concepção de História. Entre nós, tem prevalecido a ideia de que esses grupos populacionais não possuem história e, nessa perspectiva, se torna difícil compreender, ainda hoje, que a história deles faz parte da História do Brasil. É possível aceitar, apenas, que eles tiveram influências, ou então deram algumas contribuições para a vida cultural, como hábitos alimentares, para a música, ou eventos esportivos, principalmente o futebol, um dos esportes de identificação da nacionalidade (BITTENCOURT, 2016, p.199).

Como se falar em formação para o exercício da cidadania cultural nas escolas públicas se o ensino de História ainda apresenta resquícios de uma historiografia que omite ou coloca em segundo plano as práticas culturais e a condição de sujeitos/agentes históricos de uma grande parcela da população nacional? Não estaria o ensino de História negando-lhes o direito à memória individual e coletiva enquanto membros pertencentes a uma ampla gama de grupos étnico-culturais, classes sociais, comunidades locais e regionais com suas peculiaridades, apesar da preocupação da legislação, principalmente da Lei de Diretrizes e Bases da Educação 
DIREITO À MEMÓRIA, CIDADANIA CULTURAL E ENSINO DE HISTÓRIA NO CURRÍCULO OFICIAL DO ESTADO DE SÃO PAULO

Jorge Eschriqui Vieira Pinto

Nacional (LDBEN, Lei $n^{\circ}$ 9.394/96) em seu artigo $26^{3}$, com um ensino pautado na inclusão das diversas memórias e práticas culturais que fundamentam as identidades dos vários setores que compõem a sociedade brasileira? Não se estaria negando aos alunos nas instituições escolares o direito à memória histórica, ou seja, o acesso ao conjunto de bens histórico-culturais de seu grupo social, um dos pilares essenciais para a existência de uma cidadania cultural? É possível se pensar em uma escola pública engajada com a causa da inclusão social como fundamento para uma democracia plena se a totalidade dos alunos não se sente motivada, durante o processo de ensino de História, por uma aprendizagem significativa baseada em conteúdos e trabalho pedagógico integrados a aspectos histórico-culturais de seu grupo familiar, étnico, regional, social, etc.? Segundo Marcos A. Silva,

se a memória desempenha importantes papéis na definição de identidades sociais, é preciso ainda pensar sobre diferentes faces das últimas. Muitos movimentos ou grupos sociais organizados têm feito essa articulação visando aos seus projetos específicos. É o caso de feministas e negros, que contribuíram significativamente para a transformação do conhecimento histórico sobre seus respectivos grupos e muitos outros aspectos das experiências sociais, além de múltiplos outros exemplos de etnias, minorias, profissionais e demais coletividades.

A riqueza dessas experiências convida os interessados pelo prazer da História a pensar sobre possibilidades de ampliar aquelas transformações. Se os debates de contracultura e outros movimentos de massa dos anos 1960 e 1970 do século $\mathrm{XX}$ tanto significaram para a reconsideração de historicidades à luz de trajetos e projetos específicos, que se expressaram como orgulhos negro, feminino e gay, entre outros, cabe pensar sobre o caráter infinito dessas identidades insatisfeitas com a História comumente trabalhada mesmo por eruditos especialistas e a simultaneidade de identidades que marca as experiências históricas (SILVA, 2003, p.76).

\footnotetext{
${ }^{3}$ De acordo com a Lei $n^{\mathrm{o}} 11.645 / 2008$, que foi estabeleceu a escrita atual do artigo 26, parágrafo $1^{\mathrm{o}}$, da LDBEN, os conteúdos curriculares de História da educação básica devem incluir os diversos aspectos da história e cultura que caracterizam a formação da população brasileira.
} 
DIREITO À MEMÓRIA, CIDADANIA CULTURAL E ENSINO DE HISTÓRIA NO CURRÍCULO OFICIAL DO ESTADO DE SÃO PAULO

Jorge Eschriqui Vieira Pinto

A ausência de uma aprendizagem significativa dos conteúdos da disciplina de História em decorrência de um modelo tradicional de ensino caracterizado pela inexistência de uma transposição didática, ou seja, de práticas pedagógicas que conectem os conhecimentos históricos aprendidos na escola à realidade da diversidade históricocultural dos diversos segmentos sociais que compõem o corpo discente do sistema educacional brasileiro, implica em uma escola que não cria condições favoráveis para que os alunos se sintam sujeitos ativos no processo de ensino e aprendizagem e nem se percebam agentes participativos do processo histórico. Por conseguinte, isso tem contribuído para

elevar os índices de evasão e repetência de crianças provenientes dos estratos sociais mais pobres. A grande maioria adentra nos quadros escolares e sai precocemente sem concluir seus estudos no ensino fundamental por não se identificarem com uma escola moldada ainda nos padrões eurocêntricos, que não valoriza a diversidade étnico-cultural de nossa formação (FERNANDES, 2005, p.380-381).

Na realidade, há uma tendência no ambiente escolar em dissociar cultura, geralmente, associada à ideia a um saber tipicamente popular de cunho pitoresco e folclórico e dimensão local ou regional, e conhecimento, que é supervalorizado por se considerar um saber inquestionável de aplicabilidade universal e produzido por um grupo seleto de pessoas extraordinárias por sua sapiência, os cientistas. Entretanto, não há como dissociar o conhecimento, sobretudo o produzido nas Ciências Humanas, do contexto histórico-cultural no qual é gerado, afinal, a aceitação da presença da subjetividade científica é algo inquestionável no meio acadêmico. Se o conhecimento é permeado pela história de vida e profissional dos cientistas e pelo contexto sócio histórico, como se negar a influência das referências culturais do momento histórico e do meio social sobre os conhecimentos presentes nos programas curriculares das disciplinas escolares? De acordo com Circe Bittencourt,

a escola, é importante destacar, integra um conjunto de objetivos determinados pela sociedade e articula-se com eles, contribuindo para os diferentes processos econômicos e políticos, como o desenvolvimento industrial, comercial e 
DIREITO À MEMÓRIA, CIDADANIA CULTURAL E ENSINO DE HISTÓRIA NO CURRÍCULO OFICIAL DO ESTADO DE SÃO PAULO

Jorge Eschriqui Vieira Pinto

tecnológico, a formação de uma sociedade consumista, de políticas democráticas ou não.

Compreendem-se assim alguns dos objetivos gerais aos quais a escola teve de atender em determinados momentos históricos, como a formação de uma classe média pelo ensino secundário, a expansão da alfabetização pelos diferentes setores sociais ou a formação de um espírito nacionalista e patriótico. Tais objetivos estão, evidentemente, inseridos em cada uma das disciplinas e justificam a permanência delas nos currículos. As finalidades das disciplinas escolares fazem parte de uma teia complexa na qual a escola desempenha o papel de fornecedora de conteúdos de instrução, que obedecem a objetivos educacionais definidos mais amplos. Dessa forma, as finalidades de uma disciplina tendem sempre a mudanças, de modo que atendam diferentes públicos escolares e respondam às suas necessidades sociais e culturais inseridas no conjunto da sociedade (BITTENCOURT, 2008, p.42).

Portanto, não faz sentido desconectar a noção de cultura do que se entende por conhecimento científico, podendo-se até mesmo falar na existência de uma cultura científica, pois o conhecimento produzido no meio acadêmico e ensinado nas escolas faz parte do repertório cultural que possibilita a um indivíduo, um grupo social e uma sociedade se conhecerem e compreenderem à realidade que os cerca. Para o Currículo do Estado de São Paulo: Ciências Humanas e suas tecnologias,

se não rompermos a dissociação entre cultura e conhecimento não conectaremos o currículo à vida - e seguiremos alojando na escola uma miríade de atividades "culturais" que mais dispersam e confundem do que promovem aprendizagens curriculares relevantes para os alunos. [...]

Quando, no projeto pedagógico da escola, a cidadania cultural é uma de suas prioridades, o currículo é a referência para ampliar, localizar e contextualizar os conhecimentos acumulados pela humanidade ao longo do tempo. Então, o fato de uma informação ou de um conhecimento emergir de um ou mais contextos distintos na grande rede de informação não será obstáculo à prática cultural resultante da mobilização desses "saberes" nas ciências, nas artes e nas humanidades (SÃO PAULO, SE, 2012, p.11-12).

Entre as possíveis soluções para se obter um ensino de História nas escolas públicas mais comprometido com o multiculturalismo e a valorização das diferenças 
DIREITO À MEMÓRIA, CIDADANIA CULTURAL E ENSINO DE HISTÓRIA NO CURRÍCULO OFICIAL DO ESTADO DE SÃO PAULO

Jorge Eschriqui Vieira Pinto

socioculturais, pode-se citar o estímulo mais efetivo à formação complementar dos docentes já inseridos no sistema educacional por meio de cursos de pós-graduação ou extensão em estudos sobre pluralidade cultural, a obrigatoriedade por determinação do Conselho Nacional de Educação de certas disciplinas nas grades curriculares dos cursos de graduação, como por exemplo, História da África e História das Culturas Indígena e Afro-Brasileira, a inclusão nos programas de pós-graduação de linhas de pesquisas sobre a produção de novas abordagens teórico-metodológicas na educação básica sobre o tema da diversidade cultural e, sobretudo, a presença incondicional nos programas curriculares de disciplina de História de todos os Estados, do Distrito Federal e dos Municípios da questão do multiculturalismo perpassando variados conteúdos dos anos e séries do ensino fundamental e médio. Essa ênfase nos programas curriculares de História se deve ao fato de que o currículo é um instrumento educacional estratégico para a concretização e veiculação da memória e da identidade nacional em consonância com um projeto político de nação que pode representar apenas os interesses de determinados setores dominantes ou buscar atender aos anseios dos diversos grupos e classes sociais. Desse modo, podese afirmar que os programas curriculares

são uma construção e seleção de conhecimentos e práticas produzidas em contextos concretos e em dinâmicas sociais, políticas e culturais, intelectuais e pedagógicas. Conhecimentos e práticas expostos às novas dinâmicas e reinterpretados em cada contexto histórico. Os currículos são orientados pela dinâmica da sociedade (FERNANDES, 2007, p.9).

Levando-se em consideração o contexto histórico atual, a reflexão a ser feita é como se pode pensar em um Estado Democrático se os conceitos de memória e identidade nacional, que constam nos programas curriculares e materiais didáticos e que são abordados nas aulas de História nas escolas públicas, excluem práticas históricoculturais de quaisquer dos grupos sociais, étnicos e culturais do país, negando as suas contribuições no passado e no presente para a formação da sociedade nacional? Afinal, o exercício da cidadania cultural tem como pressuposto o entendimento da cultura "como trabalho da memória individual e social na criação de temporalidades diferenciadas nas quais os indivíduos, grupos e classes sociais possam reconhecer- 
DIREITO À MEMÓRIA, CIDADANIA CULTURAL E ENSINO DE HISTÓRIA NO CURRÍCULO OFICIAL DO ESTADO DE SÃO PAULO

Jorge Eschriqui Vieira Pinto

se como sujeitos de sua própria história e, portanto, como sujeitos culturais" (CHAUÍ, 1995, p.82).

Reconhecer a necessidade de um ensino de História que inclua em seus conteúdos a diversidade dos bens culturais dos grupos sociais, étnico e culturais que compõem a população nacional implica em garantir a todos os alunos a presença dos registros, vestígios e fragmentos deixados pelos seus antepassados. É isso que possibilita o desenvolvimento da memória individual e coletiva responsável pelos laços de identidade entre os estudantes e os bens culturais deixados por sua família, seu grupo étnico, sua classe social, sua comunidade local e seu país, despertando-se, assim, a valorização do aprendizado dos conteúdos de História pela percepção da relação deles com as histórias de vida dos alunos e dos membros dos segmentos sociais dos quais fazem parte. Dessa maneira, o aluno se sente parte do processo histórico, percebendo a importância da compreensão do passado para se entender os referenciais culturais de seu cotidiano e o seu papel, enquanto agente da História, na transformação consciente da sociedade. Mais do que ter o direito de acesso aos bens histórico-culturais que remetem aos grupos sociais dos quais faz parte, o estudante passa se enxergar também como um sujeito ativo da História que preserva, reproduz e produz bens culturais capazes de transformar a realidade que o cerca. Nesse sentido, de acordo com o Currículo do Estado de São Paulo: Ciências Humanas e suas tecnologias,

o desafio para quem trabalha com História consiste em extrair conhecimento de vestígios e fragmentos de humanidade que sobreviveram à passagem do tempo e a outras distâncias. Constrói-se, assim - a partir do presente, como ensinou Benedetto Croce -, uma espécie de ponte intelectual que pode nos levar aos lugares de onde viemos para saber o que e quem somos e, principalmente, o que poderíamos ser, já que um dos principais compromissos da cultura histórica é com a constante reelaboração estética do mundo social, movendo-se sempre na contramão do esquecimento (SÃO PAULO, SE, 2012, p.28-29).

A luta contra o esquecimento é uma das demandas principais na pauta de reivindicações de vários movimentos sociais que, desde o processo de redemocratização do país nos anos 1980, buscam o reconhecimento de seu papel de 
DIREITO À MEMÓRIA, CIDADANIA CULTURAL E ENSINO DE HISTÓRIA NO CURRÍCULO OFICIAL DO ESTADO DE SÃO PAULO

Jorge Eschriqui Vieira Pinto

protagonismo na sociedade brasileira por parte do poder público. Assim, movimentos feminista, negro, homossexual, de trabalhadores, etc. almejam a preservação da memória de suas práticas culturais e lutas históricas como fator essencial para a construção de suas referências identitárias de grupo e a valorização de seu protagonismo social ao longo da História contra tentativas de se relegar a um segundo plano ou mesmo negar a contribuição desses movimentos sociais para a formação histórica da sociedade nacional. Essa demanda se deve ao fato de que

a memória coletiva sempre foi posta em jogo de forma importante na luta das forças sociais pelo poder. Tornarem-se senhores da memória e do esquecimento é uma das grandes preocupações das classes, dos grupos, dos indivíduos que dominaram e dominam as sociedades históricas. Os esquecimentos e os silêncios da História são reveladores desses mecanismos de manipulação da memória coletiva (LE GOFF, 1990, p.426).

Portanto, os usos que cada indivíduo, grupo, classe social e sociedade em diversos tempos e espaços fazem dos vários aspectos histórico-culturais do passado como referenciais para a construção da memória dependem dos interesses do poder público e das demandas dos diversos segmentos sociais que lutam para que sejam reconhecidos as suas existências e protagonismo na sociedade. Em outras palavras, a memória é um artefato intelectual ou produto da construção e reconstrução mental contínua do passado a partir da seleção de determinados aspectos histórico-culturais que satisfaçam as demandas de cada indivíduo, grupo, classe social e sociedade de acordo com as exigências de cada circunstância histórica.

Não é por acaso que as legislações e os documentos oficiais sobre educação e cultura no Brasil enfatizem, neste momento histórico do país, a necessidade de se valorizar e difundir o conjunto de bens histórico-culturais que representem a diversidade dos grupos sociais, étnicos e culturais da população nacional, pois, trata-se de um contexto no qual a nação busca a consolidação do regime democrático e a cidadania plena por meio da extensão da garantia de um rol de direitos considerados fundamentais a todos os indivíduos nas mais variadas esferas da vida social. Entre esses direitos, consta-se, no caput do artigo 215, da Constituição Federal, os direitos 
DIREITO À MEMÓRIA, CIDADANIA CULTURAL E ENSINO DE HISTÓRIA NO CURRÍCULO OFICIAL DO ESTADO DE SÃO PAULO

Jorge Eschriqui Vieira Pinto

culturais que deverão ser garantidos pelo Estado das mais diversas formas, inclusive através de políticas educacionais. Diz a Carta Magna no caput do artigo citado: "O Estado garantirá a todos o pleno exercício dos direitos culturais e acesso às fontes da cultura nacional, e apoiará e incentivará a valorização e a difusão das manifestações culturais" (BRASIL, 1988, p.124).

A Base Nacional Comum Curricular (BNCC) retifica o posicionamento favorável da Constituição Federal e da Lei de Diretrizes e Bases da Educação Nacional (LDBEN, Lei $n^{\circ}$ 9.394/96) à valorização da diversidade cultural na educação básica. Por isso, propõe a pluralidade cultural como tema transversal a ser trabalhado em várias disciplinas escolares, incluindo a História, com o objetivo de contribuir para o conhecimento dos aspectos histórico-culturais dos diversos grupos sociais que compõem a população brasileira e de outros povos e nações, possibilitando-se, assim, por meio da identificação das diferenças e semelhanças entre eles, a construção de memórias e laços de identidade a partir da percepção do "nós" e do "outro". Ao mesmo tempo, pretende-se que essas diferenças culturais forneçam subsídios para o despertar nos alunos de práticas sociais de respeito à diversidade e repúdio a todas as formas de discriminação e intolerância. Segundo a Base Nacional Comum Curricular (BNCC), uma das competências gerais que se deve trabalhar didaticamente com os alunos na educação básica é

exercitar a empatia, o diálogo, a resolução de conflitos e a cooperação, fazendo-se respeitar e promovendo o respeito ao outro e aos direitos humanos, com acolhimento e valorização da diversidade de indivíduos e de grupos sociais, seus saberes, identidades, culturas e potencialidades, sem preconceitos de qualquer natureza (BRASIL, MEC, 2017, p.10).

Posicionamento similar é encontrado no Currículo Oficial do Estado de São Paulo, pois, de acordo com esse documento, é importante que a educação básica integre nas disciplinas curriculares os aspectos histórico-culturais representativos da pluralidade cultural dos segmentos sociais que compõem a população brasileira e dos quais os alunos das escolas públicas fazem parte, proporcionando-se, assim, uma aprendizagem significativa dos conteúdos escolares, ou seja, 
DIREITO À MEMÓRIA, CIDADANIA CULTURAL E ENSINO DE HISTÓRIA NO CURRÍCULO OFICIAL DO ESTADO DE SÃO PAULO

Jorge Eschriqui Vieira Pinto

para que a democratização do acesso à educação tenha função inclusiva, não é suficiente universalizar a escola: é indispensável universalizar a relevância da aprendizagem. Criamos uma civilização que reduz distâncias, tem instrumentos capazes de aproximar pessoas ou distanciá-las, aumenta o acesso à informação e ao conhecimento, mas, em contrapartida, acentua consideravelmente diferenças culturais, sociais e econômicas. Apenas uma educação de qualidade para todos pode evitar que essas diferenças se constituam em mais um fator de exclusão (SÃO PAULO, SE, 2012, p.9).

Além disso, é relevante se reconhecer, como afirma o Currículo Oficial do Estado de São Paulo, que a instituição escolar é uma representação em escala menor do multiculturalismo característico da sociedade, constituindo-se, por isso, em um espaço fundamental para um processo de socialização dos estudantes que resulte na formação para o exercício da cidadania com o aprendizado dos referenciais culturais de diferentes espaços e tempos responsáveis pela formação de sua memória individual e coletiva a partir do reconhecimento do "nós" e da diferenciação do "outro", pela intervenção consciente na realidade ao se perceberem como sujeitos que se inserem e intervêm no processo histórico-cultural e pelo respeito na convivência cotidiana às diferenças que possam existir com colegas que se inserem em outros grupos sociais, étnicos e culturais. Em outras palavras,

o desenvolvimento pessoal é um processo de agir, pensar e atuar no mundo, bem como de atribuir significados e ser percebido e significado pelos outros, apreender a diversidade, situar-se e pertencer. A educação tem de estar a serviço desse desenvolvimento, que coincide com a construção da identidade, da autonomia e da liberdade. Não há liberdade sem possibilidade de escolhas. Escolhas pressupõem um repertório e um quadro de referências que só podem ser garantidos se houver acesso a um amplo conhecimento, assegurado por uma educação geral, articuladora e que transite entre o local e global (SÃO PAULO, SE, 2012, p.9).

A aprendizagem significativa se constitui em fator motivacional para o aprendizado dos conteúdos escolares a partir do momento em que há uma transposição didática do conhecimento adquirido na escola para a realidade do aluno. Daí a importância da inclusão de temas transversais, como a pluralidade cultural, nos conteúdos das 
DIREITO À MEMÓRIA, CIDADANIA CULTURAL E ENSINO DE HISTÓRIA NO CURRÍCULO OFICIAL DO ESTADO DE SÃO PAULO

Jorge Eschriqui Vieira Pinto

disciplinas como um instrumento capaz de dar um sentido prático no dia a dia aos conhecimentos teóricos aprendidos na escola e estimular um processo de ensino e aprendizagem no qual o discente se sinta motivado a buscar gerenciar e aprofundar os seus conhecimentos, isto é, seja um sujeito ativo no processo de ensino e aprendizagem desde uma perspectiva construtivista (aprender a aprender). Entretanto, isso não quer dizer que se deva apenas abordar os aspectos históricoculturais mais próximos no espaço e no tempo dos estudantes. Pelo contrário, o acesso à cultura produzida por outros povos em diferentes espaços e tempos estimula estudos comparativos que possibilitam a percepção dos referenciais culturais na História que criam as condições para a construção da memória e dos laços de identidade a partir do reconhecimento do "nós" e diferenciação do "outro". Diferenciação que deve ser utilizada como um instrumento estratégico para a construção da identidade individual e coletiva (grupo social, local, regional, nacional), mas não como um elemento de exclusão, preconceito ou intolerância para com os indivíduos, segmentos sociais ou povos diferentes do ponto de vista cultural.

A diversidade cultural deve ser estudada como fator contribuinte para o aprendizado de uma convivência positiva com as diferenças pautado no respeito e na intervenção consciente na realidade, tendo como pressuposto a ideia de que os direitos de qualquer indivíduo em um Estado Democrático de Direito pode ser exercido até o momento que não afete os dos demais membros da coletividade (aprender a fazer e a conviver). Portanto, de acordo o Currículo do Estado de São Paulo: Ciências Humanas e suas tecnologias,

a autonomia para gerenciar a própria aprendizagem (aprender a aprender) e para a transposição dessa aprendizagem em intervenções solidárias (aprender a fazer e a conviver) deve ser a base da educação das crianças, dos jovens e dos adultos, que têm em suas mãos a continuidade da produção cultural e das práticas sociais.

Construir identidade, agir com autonomia e em relação com o outro, bem como incorporar a diversidade, são as bases para a construção de valores de pertencimento e de responsabilidade, essenciais para a inserção cidadã nas dimensões sociais e produtivas. Preparar os indivíduos para o diálogo constante com 


\section{HISTÓRIA \\ DIREITO À MEMÓRIA, CIDADANIA CULTURAL E ENSINO DE HISTÓRIA NO CURRÍCULO OFICIAL DO ESTADO DE SÃO PAULO}

Jorge Eschriqui Vieira Pinto

a produção cultural, em um tempo que se caracteriza não pela permanência, mas pela constante mudança - quando o inusitado, o incerto e o urgente constituem a regra -, é mais um desafio contemporâneo para a educação escolar (SÃO PAULO, SE, 2012, p.10).

A partir da afirmação desse documento oficial sobre o papel da escola na formação de indivíduos para o diálogo com a produção cultural, surge outra reflexão importante na discussão sobre a temática da cidadania cultural no ensino de História: Como conscientizar os alunos sobre a importância do estudo dos aspectos histórico-culturais do passado nos currículos escolares para a construção de suas memórias individuais e coletivas e a constituição dos laços de identidade em um mundo globalizado marcado por um eterno "presenteísmo" causado por ritmos de transformações tecnológicas, consumos e informações cada vez mais acelerados que criam nas novas gerações a ideia de que o passado é algo ultrapassado? Segundo Circe Bittencourt,

a escola sofre e continua sofrendo, cada vez mais, a concorrência da mídia, com gerações de alunos formados por uma gama de informações obtidas por intermédio de sistemas de comunicação audiovisuais, por um repertório de dados obtidos por imagens e sons, com formas de transmissão diferentes das que têm sido realizadas pelo professor que se comunica pela oralidade, lousa, giz, caderno e livro, nas salas de aula.

Se esse perfil diferenciado do público escolar tem apresentado desafios para educadores, no caso da História as questões se avolumaram à medida que a sociedade consumista tem se estruturado sob a égide do mundo tecnológico, responsável por ritmos de mudanças acelerados, fazendo com que tudo rapidamente se transforme em passado, não um passado saudosista ou como memória individual ou coletiva mas, simplesmente, um passado ultrapassado. Trata-se de gerações que vivem o presenteísmo de forma intensa, sem perceber os liames com o passado e que possuem vagas perspectivas em relação ao futuro pelas necessidades impostas pela sociedade de consumo que transforma tudo, incluindo o saber escolar, em mercadoria. A História oferecida para as novas gerações é a do espetáculo, pelos filmes, propagandas, novelas, desfiles carnavalescos... [...]. 
DIREITO À MEMÓRIA, CIDADANIA CULTURAL E ENSINO DE HISTÓRIA NO CURRÍCULO OFICIAL DO ESTADO DE SÃO PAULO

Jorge Eschriqui Vieira Pinto

O momento atual tem propiciado a introdução de algumas reflexões sobre a necessidade urgente do ofício do historiador e do professor de História no sentido de evitar a amnésia da sociedade atual marcada por incertezas e perspectivas indefinidas (BITTENCOURT, 2006, p.14).

O problema da "amnésia social" que compromete a constituição das identidades individuais e coletivas por parte das gerações atuais torna-se ainda mais grave quando alguns professores esquecem o compromisso da História com a memória e reforçam em sala de aula a sensação de um tempo fugidio ou eternamente presente por meio de práticas pedagógicas que não utilizam as novas Tecnologias da Informação e Comunicação (TIC) como objetos de aprendizagem para mediar e qualificar o processo de ensino e aprendizagem dos conteúdos da disciplina. Sem um planejamento de uso das TIC para um aprendizado significativo dos conteúdos de História, alguns professores adotam esses recursos educacionais apenas baseados na ideia de que as novas tecnologias prendem a atenção dos alunos por serem sinônimo de modernidade ou do novo, sem se preocuparem se realmente serão úteis ou não para uma reflexão crítica sobre o conhecimento histórico, terminando-se, assim, por colocar o pensamento analítico do passado e do presente em um segundo plano. Em outras palavras, para Jaime Pinsky e Carla Bassanezi Pinsky,

procurando acompanhar as mudanças, os novos tempos, muitos professores acabam comprando a ideia de que tudo que não é muito veloz é muito chato. Na sala de aula, o pensamento analítico é substituído por "achismos", alunos trocam a investigação bibliográfica por informações superficiais dos sites "de pesquisa" pasteurizados, vídeos são usados para substituir (e não complementar) livros. E o passado, visto como algo passado, portanto superado, tem tanto interesse quanto o jornal do dia anterior (PINSKY; PINSKY, 2016, p.17).

Essas considerações acabam por remeter à seguinte reflexão feita por Jacques Le Goff no livro História e Memória: "O passado só é rejeitado quando a inovação é considerada inevitável e socialmente desejável. Quando e como a palavra 'novo' se tornou sinônimo de 'melhor' e 'mais desejável'?” (LE GOFF, 1990, p.213). É indubitável que as novas tecnologias tem transformado radicalmente a quantidade e a velocidade da produção, disseminação e acesso às informações no mundo atual. 
DIREITO À MEMÓRIA, CIDADANIA CULTURAL E ENSINO DE HISTÓRIA NO CURRÍCULO OFICIAL DO ESTADO DE SÃO PAULO

Jorge Eschriqui Vieira Pinto

Logo, a escola já não é o único instrumento de socialização de informação para os alunos. Contudo, a escola ainda tem um papel fundamental em transformar as informações (conjunto de dados obtidos sobre um determinado assunto que pode não ser significativo para que o aluno possa conhecer a si mesmo e compreender a realidade de modo a contribuir para a sua formação e atuação consciente no meio social em que está inserido) em conhecimento (conjunto de informações compartilhadas, durante o processo de socialização do indivíduo, em quantidade e qualidade suficiente capaz de formá-lo e integrá-lo à vida em coletividade, adquirindo uma tal relevância que se internaliza e passa a fazer parte dos recursos cognitivos permanentes para a existência da pessoa no mundo).

A função da educação básica não é apenas transmitir informações, mas propiciar o acesso a um conjunto de informações que constituam conhecimentos que sejam significativos para além dos limites físicos da instituição escolar. Em suma,

é bom não confundir informação com educação. Para informar aí estão, bem à mão, jornais e revistas, a televisão, o cinema e a internet. Sem dúvida que a informação chega pela mídia, mas só se transforma em conhecimento quando devidamente organizada. E confundir informação com conhecimento tem sido um dos grandes problemas de nossa educação... Exatamente porque a informação chega aos borbotões, por todos os sentidos, é que se torna mais importante o papel do bom professor (PINSKY; PINSKY, 2016, p.22).

Ao integrar as questões da memória, identidade, pluralidade e cidadania cultural em diversos conteúdos presentes nos programas curriculares de História, criam-se as condições favoráveis para que o saber histórico da escola adquira relevância para a vida do aluno hoje e no futuro, uma vez que esse saber será um referencial para a sua formação para o exercício da cidadania pautada no conhecimento e na intervenção consciente na realidade e para a convivência respeitosa com as diferenças em seu meio social e no mundo. Para o Currículo Oficial do Estado de São Paulo,

a aprendizagem é o centro da atividade escolar. Por extensão, o professor caracteriza-se como um profissional da aprendizagem. O professor apresenta e explica conteúdos, 
DIREITO À MEMÓRIA, CIDADANIA CULTURAL E ENSINO DE HISTÓRIA NO CURRÍCULO OFICIAL DO ESTADO DE SÃO PAULO

Jorge Eschriqui Vieira Pinto

organiza situações para a aprendizagem de conceitos, de métodos, de formas de agir e pensar, em suma, promove conhecimentos que possam ser mobilizados em competências e habilidades que, por sua vez, instrumentalizam os alunos para enfrentar os problemas do mundo. Dessa forma, a expressão "educar para a vida" pode ganhar seu sentido mais nobre e verdadeiro na prática do ensino. Se a educação básica é para a vida, a quantidade e a qualidade do conhecimento têm de ser determinadas por sua relevância para a vida de hoje e do futuro, para além dos limites da escola. Portanto, mais que os conteúdos isolados, as competências são guias eficazes para educar para a vida. [...]

As novas tecnologias da informação promoveram uma mudança na produção, na organização, no acesso e na disseminação do conhecimento. A escola, sobretudo hoje, já não é a única detentora de informação, mas cabe a ela preparar seu aluno para viver em uma sociedade em que a informação é disseminada em grande velocidade. Vale insistir que essa preparação não exige maior quantidade de ensino (ou de conteúdos), mas sim melhor qualidade de aprendizagem (SÃO PAULO, SE, 2012, p.18).

Se a escola é um ambiente social propício para a mobilização de conhecimentos que podem possibilitar ao aluno condições para o seu desenvolvimento cognitivo e competências e habilidades indispensáveis para enfrentar os desafios sociais e culturais que aparecerão durante a sua vida, inserir o tema da cidadania cultural nos programas curriculares de História para a educação básica implica no desenvolvimento da conscientização sobre o valor da memória como um bem precioso para o posicionamento do estudante no mundo. A partir de práticas pedagógicas que estimulem o estudo de diversas culturas em vários espaços e tempos e o convívio respeitoso com colegas de escola que podem ter referências culturais diferentes, os alunos tomam consciência de suas historicidades, ou seja, da necessidade de salvaguardarem os referenciais culturais que estabelecem laços entre eles e os seus antepassados. Esse é o primeiro passo para o surgimento uma identidade que faça o estudante se sentir parte de um determinado segmento sócio cultural que reivindica o reconhecimento de seu protagonismo histórico-cultural na sociedade brasileira através da garantia do direito à cidadania cultural. 
DIREITO À MEMÓRIA, CIDADANIA CULTURAL E ENSINO DE HISTÓRIA NO CURRÍCULO OFICIAL DO ESTADO DE SÃO PAULO

Jorge Eschriqui Vieira Pinto

Compreendendo que a História não pode se restringir apenas à utilização da memória de certos acontecimentos considerados relevantes para a história nacional, das ações de heróis e da vida de mitos nacionais para constituir a identidade nacional, o Currículo Oficial do Estado de São Paulo propõe que a disciplina escolar contribua para a formação de uma identidade nacional pluricultural por meio do estudo das ações históricas e práticas culturais de vários indivíduos e grupos sociais, étnico e culturais que colaboraram e ainda são atuantes para a construção da História do Brasil. Esse documento estabelece algumas habilidades a serem desenvolvidas em conteúdos que incorporem a questão do direito à memória e à cidadania cultural no ensino fundamental e médio, favorecendo-se a uma prática de ensino que enfatiza a História como uma contínua construção política, social e cultural, da qual participam diversos sujeitos:

*Elaborar o conceito de memória, reconhecendo sua importância para a construção do conhecimento histórico $\left(6^{\circ}\right.$ ano do ensino fundamental - Conteúdos: Sistemas sociais e culturais de notação de tempo ao longo da História; As linguagens das fontes históricas; A vida na Pré-História e a escrita; Os suportes e os instrumentos das escrita);

${ }^{*}$ Reconhecer a importância das manifestações culturais do presente e as raízes históricas de sua constituição. Identificar as principais contribuições das culturas antigas - em seus múltiplos aspectos - para a conformação das sociedades contemporâneas ( $6^{\circ}$ ano do ensino fundamental - Conteúdos: Civilizações do Oriente Próximo; África, o "berço da humanidade"; Heranças culturais da China e trocas culturais em diferentes épocas);

* Reconhecer a importância da preservação da memória para o conhecimento da História da humanidade $\left(6^{\circ}\right.$ ano do ensino fundamental - Conteúdos: A vida na Grécia Antiga; A vida na Roma Antiga);

${ }^{*}$ Reconhecer os elementos socioculturais que constituem as identidades, a partir do estudo das questões de alteridade $\left(6^{\circ}\right.$ ano do ensino fundamental - Conteúdos: o fim do Império Romano; As civilizações do Islã: sociedade e cultura; Império Bizantino e o Oriente no imaginário medieval);

*Estabelecer relações entre as manifestações culturais do presente e as raízes históricas de sua constituição. Reconhecer, 
Jorge Eschriqui Vieira Pinto

a partir de diferentes referências, a importância da cultura material como fonte histórica $\left(7^{\circ}\right.$ ano do ensino fundamental Conteúdos: O Feudalismo; As Cruzadas e os contatos entre as sociedades europeias e orientais; Renascimento Comercial e Urbano; Renascimento Cultural e Científico);

${ }^{*}$ Associar as manifestações culturais do presente aos processos históricos de sua constituição. Comparar diferentes pontos de vista sobre situações de natureza histórico-cultural, identificando os pressupostos de cada interpretação e analisando a validade dos argumentos utilizados. Reconhecer a importância do estudo das questões de alteridade para compreender as relações de caráter histórico-cultural a partir da compreensão dos elementos culturais que constituem as identidades $\left(2^{\mathrm{a}}\right.$ série do ensino médio - Conteúdos: Renascimento; Reforma e Contrarreforma; Encontros entre europeus e as civilizações da África, da Ásia e da América);

*Estabelecer relações entre as manifestações do pensamento e da criação artístico-literária aos seus contextos históricos específicos. Reconhecer a importância das manifestações do pensamento para identificar os modos de vida das sociedades ao longo da História ( $2^{\mathrm{a}}$ série do ensino médio - Conteúdos: Revolução Inglesa; Iluminismo; Independência dos Estados Unidos da América);

* Relacionar o princípio de respeito aos valores humanos à diversidade sociocultural nas análises de fatos e processos histórico-sociais. Comparar pontos de vista expressos em diferentes fontes sobre um determinado aspecto da cultura. Interpretar realidades histórico-sociais a partir de conhecimentos sobre a economia e as práticas sociais e culturais. Reconhecer alternativas de intervenção em conflitos sociais e crises institucionais que respeitem os valores humanos e a diversidade sociocultural. Discutir situações da vida cotidiana relacionadas a preconceitos étnicos, culturais, religiosos e de qualquer outra natureza ( $3^{a}$ série do ensino médio - Conteúdos: Imperialismos; Primeira Guerra Mundial; Nazismo e racismo);

*Interpretar os significados de diferentes manifestações populares como representação do patrimônio regional e cultural ( $3^{\mathrm{a}}$ série do ensino médio - Conteúdo: As manifestações culturais de resistência aos governos autoritários nas décadas de 1960 e 1970) (SÃO PAULO, SE, 2012, p.39, 40, 41, 42, 43, $64,65,69,72$ ). 
DIREITO À MEMÓRIA, CIDADANIA CULTURAL E ENSINO DE HISTÓRIA NO CURRÍCULO OFICIAL DO ESTADO DE SÃO PAULO

Jorge Eschriqui Vieira Pinto

Portanto, de acordo com o Currículo Oficial do Estado de São Paulo, o saber histórico ensinado nas salas de aula não deve se utilizar da seleção de conteúdos significativos para a aquisição de competências e habilidades a serem estimuladas nos alunos como parâmetro para a negação ou o menosprezo de aspectos histórico-culturais de determinados segmentos sociais ou de certas sociedades durante o processo de ensino e aprendizagem.

A sociedade brasileira atual demanda a uma identidade nacional plural que consiga incorporar as memórias e as particularidades de diversos grupos sociais, étnicos e culturais. Nesse sentido, o ensino de História tem um papel fundamental na construção de uma identidade nacional que seja pluricultural, desde que oportunize um saber histórico nas escolas que incorpore as especificidades e peculiaridades das culturas locais, regionais e dos vários segmentos sociais.

\section{Referências Bibliográficas:}

BITTENCOURT, Circe Maria Fernandes. Capitalismo e cidadania nas atuais propostas curriculares de História. In: $\mathbf{O}$ saber histórico na sala de aula. 11 ed. São Paulo: Contexto, 2006, p.11-27.

. Ensino de História: fundamentos e métodos. 2 ed. São Paulo:

Cortez, 2008. . Identidade nacional e ensino de História do Brasil. In: História na sala de aula: conceitos, práticas e propostas. 6 ed. São Paulo: Contexto, 2016, p.185204.

BRASIL. Ministério da Educação. Secretaria de Educação Básica. Base Nacional Comum Curricular: educação é base. Brasília: MEC/SEB, 2017.

Constituição da República Federativa do Brasil. Disponível em: <http://www.planalto.gov.br/ccivil_03/constituicao/constituicao.htm>. Acesso em: 14 de janeiro de 2018. 
DIREITO À MEMÓRIA, CIDADANIA CULTURAL E ENSINO DE HISTÓRIA NO CURRÍCULO OFICIAL DO ESTADO DE SÃO PAULO

Jorge Eschriqui Vieira Pinto

Lei de Diretrizes e Bases da Educação Nacional. Disponível em: <http://www.planalto.gov.br/ccivil_03/leis/L9394.htm>. Acesso em: 14 de janeiro de 2018.

CHAUÍ, Marilena. Cultura política e política cultural. Estudos Avançados. São Paulo: USP, v. 9, n²3, p.71-84, 1995.

FERNANDES, Cláudia de Oliveira. Indagações sobre currículo: currículo e avaliação. Brasília: Ministério da Educação; Secretaria de Educação Básica, 2007.

FERNANDES, José Ricardo Oriá. Educação patrimonial e cidadania: uma proposta alternativa para o ensino de História. Revista Brasileira de História. São Paulo: ANPUH, v. 13, n² 25/26, p. 265-276, set. 1992/ ago. 1993.

. Ensino de História e diversidade cultural: desafios e possibilidades.

Caderno Cedes. Campinas: UNICAMP, v. 25, nº 67, p.378-388, set./dez. 2005.

LE GOFF, Jacques. História e memória. Trad. Bernardo Leitão. Campinas: Editora da UNICAMP, 1990.

PINSKY, Jaime; PINSKY, Carla Bassanezi. O que e como ensinar: por uma História prazerosa e consequente. In: História na sala de aula: conceitos, práticas e propostas. 6 ed. São Paulo: Contexto, 2016, p.17-36.

SÃO PAULO. Secretaria de Educação. Currículo do Estado de São Paulo: Ciências Humanas e suas tecnologias. São Paulo: SE, 2012.

SILVA, Marcos A. História: o prazer em ensino e pesquisa. São Paulo: Brasiliense, 2003.

VEIGA NETO, Alfredo. Cultura, culturas e educação. Revista Brasileira de Educação. Rio de Janeiro: ANPED, n² 23, p.5-15, maio/ jun./ jul./ ago. 2003.

Educação e Pós-modernidade: impasses e perspectivas. Resumo da

Aula Inaugural no Programa de Pós-Graduação em Educação da Pontifícia Universidade Católica do Rio de Janeiro. Rio de Janeiro: PPG-Educação/PUC-Rio, 


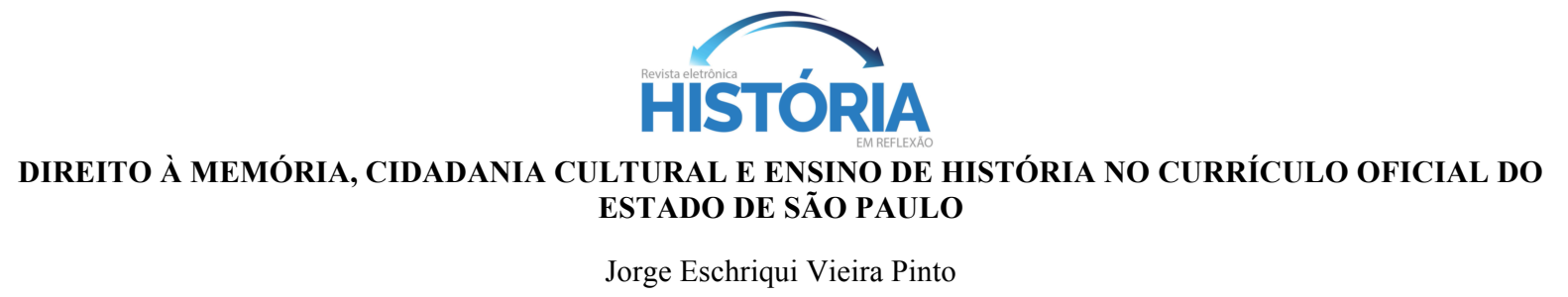

mar. 2005. Disponível em: <https://www.maxwell.vrac.puc-rio.br/8708/8708.PDF>. Acesso em: 14 jul. 2018, p.8.

Artigo recebido em 28/07/2018

Artigo aceito em 16/01/2019 